\title{
Effect of systemic injection of heterogenous and homogenous opioids on peripheral cellular immune response in rats with bone cancer pain: A comparative study
}

\author{
JUN-YING DU* , YI LIANG ${ }^{*}$, JUN-FAN FANG, YONG-LIANG JIANG, \\ XIAO-MEI SHAO, XIAO-FEN HE and JIAN-QIAO FANG \\ Department of Neurobiology and Acupuncture Research, The Third Clinical Medical College, \\ Zhejiang Chinese Medical University, Hangzhou, Zhejiang 310053, P.R. China
}

Received May 7, 2015; Accepted June 23, 2016

DOI: $10.3892 /$ etm.2016.3647

\begin{abstract}
Exogenous and endogenous opioids have been shown to modulate the immune system. Morphine-induced immunosuppression has been investigated extensively. However, the immune-regulating function of endogenous opioid peptides is unclear. The present study aimed to evaluate the difference in effects on cellular immune function between recombinant rat $\beta$-endorphin $(\beta$-EP; $50 \mu \mathrm{g} / \mathrm{kg})$ and plant source morphine $(10 \mathrm{mg} / \mathrm{kg})$ via intraperitoneal injection treatment in a rat model of bone cancer pain. Walker 256 cells were injected into a tibial cavity injection to establish the bone cancer pain model. The paw withdrawal thresholds and body weights were measured prior to surgery, at 6 days after surgery, and following 1, 3,6 and 8 treatments. The spleen cells were harvested for detection of $\mathrm{T}$ cell proliferation, natural killer $(\mathrm{NK})$ cell cytotoxicity, and the relative quantities of $\mathrm{T}$ cell subtypes $\left(\mathrm{CD}^{+}, \mathrm{CD}^{+}\right.$and $\mathrm{CD}^{+}$cells). Plasma levels of interleukin-2 (IL-2) were also determined. It was found that single or multiple treatments with $\beta$-EP (a homogenous opioid peptide) and morphine (a heterogenous opioid) had good analgesic effects on bone cancer pain, while the analgesia provided by morphine was stronger than that of $\beta$-EP. Treatment with $\beta$-EP 3, 6 and 8 times increased the body weight gain in the rat model of bone cancer pain, while morphine treatment had on effect on it. With regard to immunomodulatory functions, $\beta$-EP treatment increased T cell proliferation and NK cell cytotoxicity, and increased the relative quantities of $\mathrm{T}$ cell subtypes,
\end{abstract}

Correspondence to: Professor Jian-Qiao Fang, Department of Neurobiology and Acupuncture Research, The Third Clinical Medical College, Zhejiang Chinese Medical University, 548 Binwen Road, Binjiang, Hangzhou, Zhejiang 310053, P.R. China E-mail: fangjianqiao7532@163.com

*Contributed equally

Key words: bone cancer pain, cellular immune, heterogenous, homogenous, opioid peptide but no effect on T cell secretion. However, morphine treatment decreased $\mathrm{T}$ cell proliferation and the levels of $\mathrm{T}$ cell subtypes. These data indicate that opioids from different sources have different effects on cellular immune function in vivo. A small dose of homogenous opioid peptide exhibited positive effects (analgesia and immune enhancement) on cancer pain. These results provide experimental evidence supporting the exploitation of human opioids for the treatment of cancer pain.

\section{Introduction}

In patients with cancer, pain is a common symptom and the major factor responsible for decreasing the quality of life $(1,2)$. A number of studies concerning the prevalence of pain in cancer patients have shown that $24-60 \%$ of patients undergoing active anticancer treatment $(3,4)$ and $62-86 \%$ of terminal cancer patients $(5,6)$ suffer from burdensome pain symptoms. The unique pathophysiology of cancer pain causes it to exceed that of a combination of inflammatory and neuropathic pain (7). In addition, there is evidence suggesting that patients with chronic pain always exhibit immune suppression symptoms (8). It has been suggested that the levels of $\mathrm{CD}^{+} \mathrm{T}$ cells in the serum of patients with cancer pain are decreased (9). Therefore, cancer pain and immune suppression are two main symptoms in cancer patients.

Opioids are used widely to treat acute pain following extensive surgery and many kinds of chronic pain, particularly cancer pain (10-13). It is known that opioids not only result in analgesia but also modulate the immune system (14). Opioids include endogenous opioid peptides and exogenous opiates. There is growing evidence that acute and long-term administration of exogenous opiates, especially morphine, which is a heterogenous opioid, mediates immunosuppression (15). However, the effects of endogenous opioids on the immune system remain a subject of debate, with some reports that endogenous opioids promote the immune function and others supporting the opposite view $(15,16)$.

Although numerous studies have observed the effects of opioid drugs on immune responses, the clinical relevance of these observations for heterogenous and homogenous opioids remains uncertain. Few studies have analyzed the association 
between opioids and the immune system in vivo. To address this, in the present study, Walker 256 cells were injected into a tibial cavity in rats to establish a bone cancer pain model. Recombinant rat $\beta$-endorphin $(\beta$-EP; $50 \mu \mathrm{g} / \mathrm{kg})$ and plant-derived morphine $(10 \mathrm{mg} / \mathrm{kg})$ were administered by intraperitoneal injection and the analgesic effects were compared. In addition, the effects of the opioids on cellular immune function, specifically $\mathrm{T}$ lymphocyte proliferation, natural killer $(\mathrm{NK})$ cell cytotoxicity and the levels of $\mathrm{T}$ cell subgroups in the bone cancer pain models were examined, and the differences between the effects on cellular immune function were compared between the heterogenous and homogenous opioid treatment groups. The aim of this study was to provide scientific evidence useful in the development of human opioids to treat cancer pain.

\section{Materials and methods}

Animals. A total of 40 adult female Sprague-Dawley (SD) rats weighing (150-170 g; Shanghai SLAC Laboratory Animal Co., Ltd, Shanghai, China) and 10 female SD rats (weight, 70-80 g; Shanghai SLAC Laboratory Animal Co., Ltd.) were raised in a 12-h light/dark cycle with access to plentiful amounts of food and water. They were housed five per cage and were acclimatized for 1 week prior to behavioral studies. Efforts were made to minimize animal discomfort and reduce the numbers of animals used. The animal protocols were approved by the Animal Ethics Committee at Zhejiang Chinese Medical University (Hangzhou, China).

Surgery. Walker 256 cells $\left(1 \times 10^{7}\right.$; The Cell Bank of Type Culture Collection of Chinese Academy of Sciences, Shanghai, China) were administered by intraperitoneal injection into the abdominal cavity of juvenile rats (70-80 g). After 7 days, ascites were generated in the peritoneal cavity and carcinoma cells were harvested through sterile syringes. The percentage of cellular activity was checked to ensure that it was $>95 \%$, as measured using a TC10 ${ }^{\mathrm{TM}}$ Automated Cell Counter (Bio-Rad Laboratories, Inc., Hercules, CA, USA).

Female SD rats were anesthetized by the administration of $10 \%$ chloral hydrate $(0.35 \mathrm{ml} / 100 \mathrm{~g})$ intraperitoneally, and then placed in a supine position. The left leg of the rat was shaved and the skin sterilized with iodophor and $75 \%$ ethanol. A 1-cm rostro-caudal incision was then made in the skin in the upper half of the tibia. The tibia was carefully exposed with minimal damage to the muscle and blood vessels. A 21-gauge needle was inserted at the site of intercondylar eminence at a $30-45^{\circ}$ angle and pierced $5 \mathrm{~mm}$ below the knee joint into the medullary cavity of the tibia. The needle was then removed and replaced with a $10-\mu 1$ syringe (Hamilton Co., Bonaduz, Switzerland) containing the carcinoma cells $\left(3 \times 10^{5}\right)$ to be injected into the tibial cavity. The syringe was kept in position for 2 min prior to removal from the tibial cavity to prevent cells from leaking out along the injection hole. The injection site was quickly sealed using bone wax and the wound was closed with stitches. Penicillin (20,000 units, intramuscular injection) was given to avoid infection.

Rats of the sham surgery group were injected with the same volume of phosphate-buffered saline (PBS) into the tibial cavity, and the other protocols were the same as those used in the surgery group.
Experimental groups. The rats were separated randomly into four groups: i) Sham surgery group $(n=10)$; ii) surgery group $(\mathrm{n}=10)$; iii) morphine group $(\mathrm{n}=10)$; and iv) $\beta$-EP group $(\mathrm{n}=10)$.

Paw withdrawal thresholds (PWTs). The PWTs were observed at six time points: Baseline (prior to surgery), at 6 days after surgery and following 1, 3, 6, and 8 treatments (as described below). As in a previous study (17), rats were adapted to the new environment by being placed on a metal mesh table. A mechanical stimulus (force $0-50 \mathrm{~g}$ over a $20 \mathrm{sec}$ time period) was delivered to the plantar surface of the left hind paw using a Dynamic Plantar Aesthesiometer (37450; Ugo Basile, Monvalle, Italy). When the animal withdrew its hind paw, the mechanical stimulus was automatically stopped, and the force at which the animal withdrew its paw was recorded as the PWT. Withdrawal responses were taken from four consecutive trials with $\geq 3$ min between trials and averaged.

Administration of treatments. Immediately after finishing the measurement of PWTs on 6 day, rats in the morphine group were intraperitoneally injected once every other day with $10 \mathrm{mg} / \mathrm{kg}$ morphine hydrochloride injection (C81004-2; Northeast Pharmaceutical Group Shenyang No. 1 Pharmaceutical Co., Ltd., Shenyang, China) and rats in the $\beta$-EP group were injected intraperitoneally with $50 \mu \mathrm{g} / \mathrm{kg} \beta$-EP $(\mathrm{H}-284$; Bachem AG, Hauptstrasse, Switzerland) for 15 days, once every other day. Sham surgery and surgery groups did not received any treatment.

Body weight measurements. The body weights of the rats were measured at baseline, at 6 days after surgery and following 1, 3,6 , and 8 treatments. The increase in body weight was calculated as follows: Body weight growth rate $(\%)=$ measured value/basal value $\mathrm{x} 100$.

Extraction of splenic monocytes. Rats were sacrificed by cervical dislocation after the last PWT had been measured. The dead rats were soaked into $75 \%$ alcohol, and then moved onto a super clean bench. The spleen was excised, soaked in RPMI-1640 medium, HEPES [RPMI-1640 supplemented with $10 \%$ fetal bovine serum (FBS), 10,000 U/ml penicillin $\mathrm{G}$ and $10,000 \mu \mathrm{g} / \mathrm{ml}$ streptomycin; Thermo Fisher Scientific, Inc., Waltham, MA, USA] for $20 \mathrm{~min}$. The spleen was placed on a 200-mesh stainless steel screen, cut into pieces and then ground, using PBS (sterile) to keep the tissue moist during the whole experiment. The obtained cell suspension was combined with 3-5 volumes of red blood cell lysis buffer (Beyotime Institute of Biotechnology, Haimen, China), and mixed gently. After standing for $2 \mathrm{~min}$, the suspension was centrifuged at room temperature for $10 \mathrm{~min}$ at $1,000 \mathrm{~g}$, and the supernatant was discarded. The obtained cell suspension was combined with 5 volumes of PBS (sterile), mixed gently, then centrifuged at room temperature for $10 \mathrm{~min}$ at $1,000 \mathrm{x} \mathrm{g}$, twice. Cells were suspended in RPMI-1640 (10\% FBS, $100 \mathrm{U} / \mathrm{ml}$ penicillin G and $100 \mu \mathrm{g} / \mathrm{ml}$ streptomycin) after cleaning, and the concentration of the cell suspension was adjusted to $1 \times 10^{6} / \mathrm{ml}$.

T lymphocyte proliferation assays. Splenic monocytes were seeded into 96 -well plates at $2 \times 10^{5}$ cells/well in triplicate. For the test samples, $20 \mu \mathrm{l}$ concanavalin A (ConA; $10 \mu \mathrm{g} / \mathrm{ml}$; 
Sigma-Aldrich, St. Louis, MO, USA) was added to each well. For the control, $20 \mu \mathrm{l}$ RPMI-1640 was added to three wells. The plates were incubated at $37^{\circ} \mathrm{C}$ for $72 \mathrm{~h}$. Cell viability was assessed using Cell Counting kit-8 (CCK-8; Beyotime Institute of Biotechnology) and according to the manufacturer's protocol. WTS-8 $(20 \mu \mathrm{l})$ was added to each well and plates were incubated at $37^{\circ} \mathrm{C}$ for $4 \mathrm{~h}$. The absorbance of each sample was measured at $450 \mathrm{~nm}$ using a microtiter plate reader (SpectraMax M4; Molecular Devices, LLC, Sunnyvale, CA, USA). The reference wavelength was $>650 \mathrm{~nm}$. The T lymphocyte proliferation function was determined using the following equation: $\mathrm{T}$ lymphocyte activity $(\%)=$ absorbance of test sample/absorbance of control x 100.

NK cell cytotoxicity assays. YAC-1, a mouse lymphoma cell line, was purchased from Shanghai Institutes for Biological Sciences, Chinese Academy of Sciences (No. TCM28; Shanghai, China). Cells were grown in suspension in a culture bottle (Corning Incorporated, Corning, NY, USA), with RPMI-1640 medium, HEPES (RPMI-1640 supplemented with $10 \% \mathrm{FBS}, 100 \mathrm{U} / \mathrm{ml}$ penicillin $\mathrm{G}$ and $100 \mu \mathrm{g} / \mathrm{ml}$ streptomycin). Only cells in the exponential growth phase were used for cytotoxicity assays. The YAC-1 cells were used as sensitive target cells for the evaluation of NK cell cytotoxicity in vitro (18). Determination of NK cell function was implemented using an enzymatic colorimetric technique involving lactate dehydrogenase (LDH) release (LDH-cytotoxicity assay kit; BioVision, Inc., Milpitas, CA, USA).

Splenic monocytes as effector cells were incubated in RPMI-1640 medium, HEPES (RPMI-1640 supplemented with $10 \% \mathrm{FBS}, 100 \mathrm{U} / \mathrm{ml}$ penicillin $\mathrm{G}$ and $100 \mu \mathrm{g} / \mathrm{ml}$ streptomycin). Viability of effector and target cells was determined by the trypan blue dye exclusion test prior to the cytotoxicity test to confirm that the viability was $>95 \%$. In the test sample, the effector cells at a concentration of $1 \times 10^{6}$ in $100 \mu$ culture medium were mixed with $100 \mu 1$ YAC-1 cells at a concentration of $2 \times 10^{4}$, resulting in an effector cell:target cell ratio of 50:1. As the background control, $200 \mu \mathrm{l}$ medium/well was added to triplicate wells (the background value was subtracted from all other values). As the low control, $1 \times 10^{6}$ cells/well in $200 \mu \mathrm{l}$ culture medium were added to triplicate wells. As the high control, $1 \times 10^{6}$ cells/well in $200 \mu \mathrm{l}$ culture medium containing 1\% Triton X-100 were added to triplicate wells. Each test sample and all controls were evaluated in triplicate in 96-micro-well plates, and incubated at $37^{\circ} \mathrm{C}$ in a thermostatic incubator with $5 \% \mathrm{CO}_{2}$ for $4 \mathrm{~h}$. The micro-well plates were centrifuged at $250 \mathrm{x}$ g for $10 \mathrm{~min}$, and the supernatant was isolated. The $\mathrm{LDH}$ reaction mixture was added and maintained for $30 \mathrm{~min}$ at room temperature with the absence of light. The absorbance was measured using the SpectraMax M4 reader at $490 \mathrm{~nm}$ and the percentage of cytotoxicity was determined using the following equation: Cytotoxicity $(\%)=$ [absorbance (test sample - background control - low control)]/[absorbance (high control - low control)] x 100.

Flow cytometry assay. Spleen cell suspensions were collected from the cell culture bottles, and were adjusted to a concentration of $1-5 \times 10^{6}$ cells $/ \mathrm{ml}$. Fluorescein isothiocyanate (FITC)-conjugated anti-rat CD3 monoclonal antibody (cat. no. E00051-1631; eBioscience, Inc., San Diego, CA, USA),

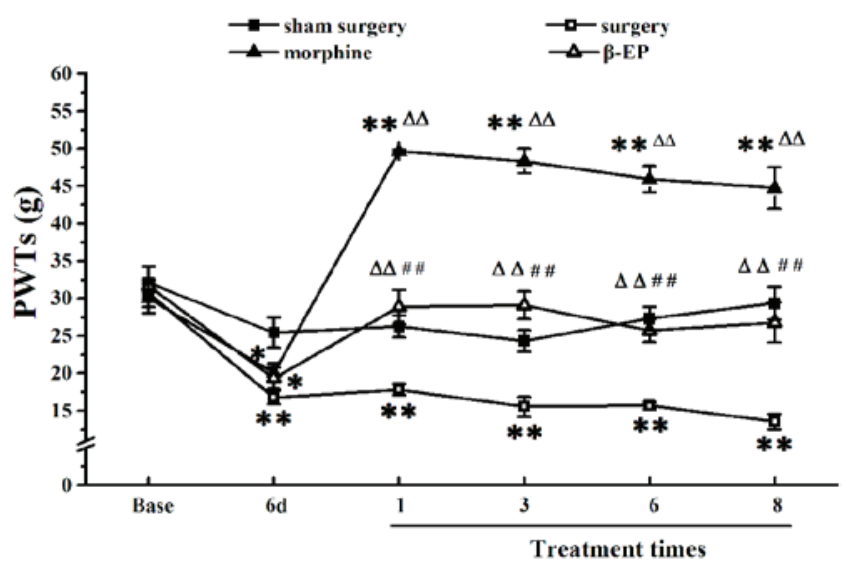

Figure 1. Effect of opioid treatment on the PWTs in an animal model of bone cancer pain. The analgesic effect of morphine on allodynia was stronger than that of $\beta$-EP. ${ }^{*} \mathrm{P}<0.05$ and ${ }^{* *} \mathrm{P}<0.01$ vs. the sham surgery group; ${ }^{\Delta \Delta} \mathrm{P}<0.01$ vs. the surgery group; ${ }^{*} \mathrm{P}<0.01$ vs. the morphine group. $\mathrm{n}=8-10$. PWTs, paw withdrawal thresholds; $\beta$-EP, $\beta$-endorphin; $6 \mathrm{~d}, 6$ day.

allophycocyanin (APC)-conjugated anti-rat CD4 monoclonal antibody ((E07034-1632; eBioscience, Inc.) and phycoerythrin (PE)-conjugated anti-rat CD8a monoclonal antibody (cat. no. E01045-1633; eBioscience, Inc.) were used for T cell, helper $\mathrm{T}$ cell and cytotoxic $\mathrm{T}$ cell detection respectively. Spleen cell suspensions were added to the $100 \mu$ l paraformaldehyde solution and were incubated with the above-mentioned antibodies for $15 \mathrm{~min}$ at $4^{\circ} \mathrm{C}$. The cells were then washed three times with PBS, and $500 \mu 1$ PBS was added to resuspend the cells. $\mathrm{CD}^{+}, \mathrm{CD}^{+}$and $\mathrm{CD} 8 \mathrm{a}^{+}$cell analysis was performed within the lymphocyte cell range. The data were analyzed using BD FACSCanto II software (BD Biosciences, Franklin Lakes, NJ, USA). PBS was substituted for the antibody to serve as the control. Monoclonal mouse IgG3 Isotype Control FITC (cat. no. E11772-1632; eBioscience, Inc.), mouse IgG2a K Isotype Control APC (cat. no. E11418-1633; eBioscience, Inc.) and mouse IgG1 K Isotype Control PE (cat. no. E11418-1633; eBioscience, Inc.) were used as the respective isotype controls.

Enzyme linked immunosorbent assay (ELISA) for plasma interleukin (IL)-2. Plasma was analyzed to determine IL-2 levels using a Quantikine ${ }^{\circledR}$ ELISA kit (R\&D Systems Europe, Ltd., Abingdon, UK) according to manufacturer's protocol. All samples were run on one 96-well plate for each variable. Plasma IL-2 levels were measured using the SpectraMax M4 microplate reader. Each sample was measured in triplicate.

Statistical analysis. All data are expressed as the mean \pm standard error of the mean. The PWTs were analyzed using a two-way analysis of covariance (ANOVA) with repeated measures. One-way ANOVA with post hoc multiple comparisons was applied to identify differences between experimental groups. $\mathrm{P}<0.05$ was considered to indicate a statistically significant difference.

\section{Results}

Effects of opioids on PWTs in a rat model of bone cancer pain. As shown in Fig. 1, there were no differences of basal PWTs 


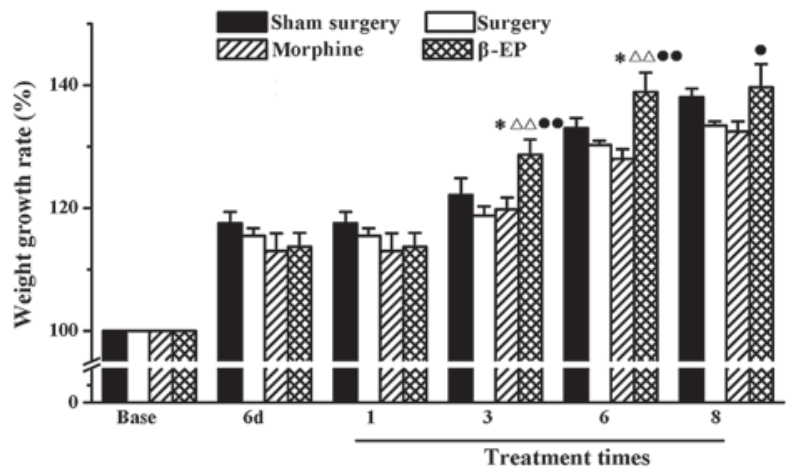

Figure 2. Effect of opioid treatment on percentage weight increase in a rat model of bone cancer pain. Intraperitoneal injection of $\beta$-EP increased the rate of weight gain of bone cancer pain model rats (surgery group), however, intraperitoneal morphine did not have a similar effect. ${ }^{~} \mathrm{P}<0.05$ vs. the sham surgery group; ${ }^{\Delta \Delta} \mathrm{P}<0.01$ vs. the surgery group; ${ }^{\circ} \mathrm{P}<0.05$ and ${ }^{*} \mathrm{P}<0.01$ vs. the morphine group. $n=8-10$. $\beta$-EP, $\beta$-endorphin; $6 \mathrm{~d}, 6$ day.

among the sham surgery, surgery, morphine and $\beta$-EP groups $(\mathrm{P}>0.05)$. Compared with the sham surgery group, the injection of Walker 256 cells into the tibial cavity in the surgery group induced a marked reduction of the PWT in the ipsilateral hind paw at 6 days $(\mathrm{P}<0.01)$. After receiving treatment 1 , 3, 6 and 8 times, the PWTs of the $\beta$-EP and morphine group were markedly increased compared with those of the surgery group $(\mathrm{P}<0.01)$. The PWTs of the morphine group were the most increased, being higher than those of the $\beta$-EP group at any time of treatment $(\mathrm{P}<0.01)$.

Effects of opioids on body weight increase in a rat model of bone cancer pain. The percentage increase in body weight of the rats in each group was determined. As shown in Fig. 2, the weight increase in the sham surgery, surgery, morphine and $\beta$-EP groups were not different prior to surgery, on 6 day after surgery, and following one treatment. After treatment 3 and 6 times, the percentage increase in body weight of the $\beta$-EP group was higher than that of the sham surgery $(\mathrm{P}<0.05)$, surgery $(\mathrm{P}<0.01)$ and morphine groups $(\mathrm{P}<0.01)$. After 8 treatments, the percentage increase of body weight in the $\beta$-EP group was higher than that of the morphine group only $(\mathrm{P}<0.05)$.

Effects of opioids on T cell proliferation in the splenic lymphocytes of a rat model of bone cancer pain. A Cell Counting kit- 8 assay was conducted to observe the $\mathrm{T}$ cell growth rate of the spleen, with measurement of the optical density for splenic lymphocytes incubated with WST- 8 for $4 \mathrm{~h}$. As shown in Fig. 3, compared with the sham surgery group, the $\mathrm{T}$ cell growth rates of the surgery group and morphine group were significantly decreased $(\mathrm{P}<0.05$ and $\mathrm{P}<0.01$, respectively), and there was no significant difference between the surgery and morphine groups $(\mathrm{P}>0.05)$. Compared with morphine group, the $\mathrm{T}$ cell growth rate of the $\beta$-EP group was significantly increased $(\mathrm{P}<0.05)$.

Effects of opioids on NK cell cytotoxicity in splenic lymphocytes of a rat model of bone cancer pain. An assay involving $\mathrm{LDH}$ release was used to measure the cytotoxicity of NK cells in the spleen. As shown in Fig. 4, there were no significant differences of spleen NK cell cytotoxicity among the sham

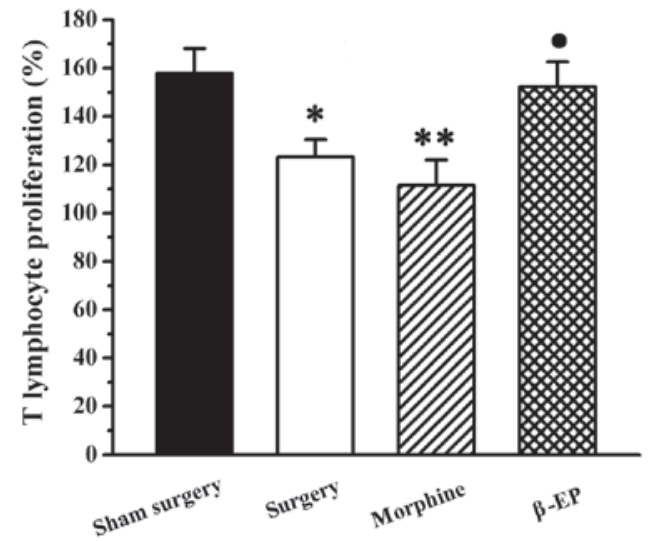

Figure 3. Effect of treatment with two different opioids on T lymphocyte proliferation in a rat model of bone cancer pain. $\mathrm{T}$ lymphocyte proliferation in the $\beta$-EP group was stronger than that of the morphine group. " $\mathrm{P}<0.05$ and ${ }^{* *} \mathrm{P}<0.01$, vs. the sham surgery group; ${ }^{\circ} \mathrm{P}<0.05$ vs. the morphine group. $\mathrm{n}=8-10 . \beta$-EP, $\beta$-endorphin.

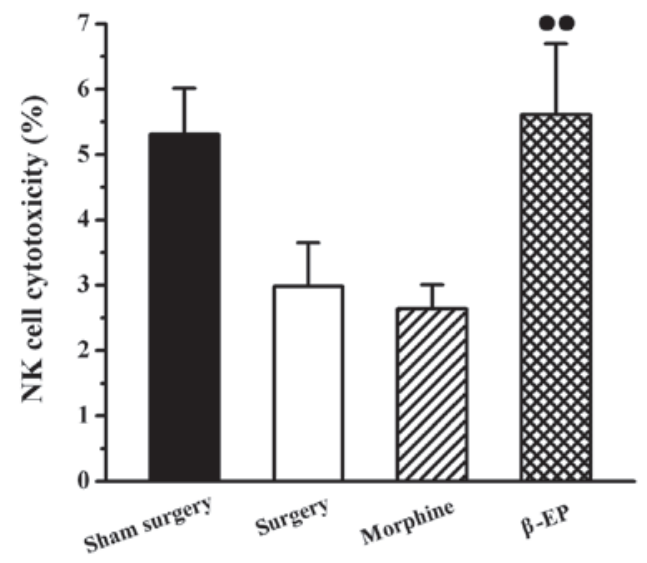

Figure 4. Effect of opioid treatment on NK cell cytotoxicity in a rat model of bone cancer pain. NK cell cytotoxicity of the $\beta$-EP group was stronger than that of the morphine group. " $\mathrm{P}<0.01$ vs. the morphine group. $\mathrm{n}=8-10$. $\beta$-EP, $\beta$-endorphin; NK, natural killer.

surgery, surgery and morphine groups. The NK cell cytotoxicity of the spleen in the $\beta$-EP group was stronger than that of the morphine group $(\mathrm{P}<0.05)$.

Effects of opioids on levels of $T$ cell subtypes $\left(\mathrm{CD}^{+}, \mathrm{CD}^{+}\right.$ and $C D 8^{+}$cells) in splenic lymphocytes of a rat model of bone cancer pain. Flow cytometry was used to assay the content of $\mathrm{CD}^{+}, \mathrm{CD}^{+}$and $\mathrm{CD}^{+}$cells in splenic lymphocytes among the sham surgery, surgery, morphine and $\beta$-EP groups. As shown in Fig. 5, the percentage of $\mathrm{CD}^{+}$cells in the splenocytes of the surgery group was decreased compared with that in the sham surgery group, but the reduction was not statistically significant. When the surgery and morphine groups were compared with the $\beta$-EP group, the differences in $\mathrm{CD}^{+}$cell percentages were significant $(\mathrm{P}<0.05$ and $\mathrm{P}<0.01$, respectively). The percentage of $\mathrm{CD}^{+}$cells in the $\beta$-EP group was greater than that in the surgery and morphine groups, and there was no significant difference between the surgery and morphine groups. The results for $\mathrm{CD} 4^{+}$ and $\mathrm{CD}^{+}$percentages in the splenic lymphocytes were similar to those for CD3 (Figs. 6 and 7). 
A

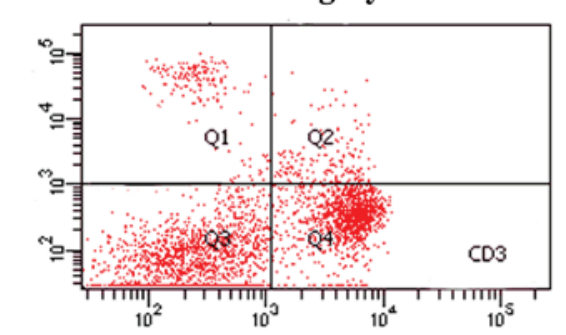

C

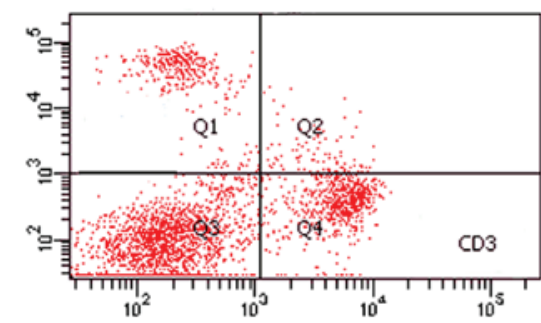

B

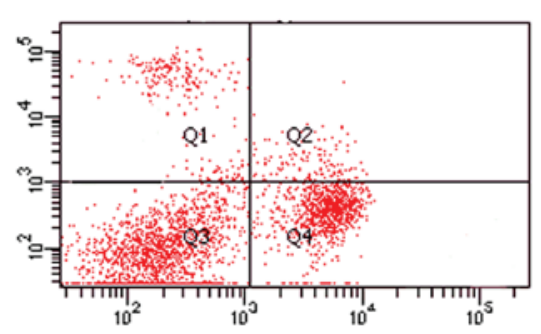

D

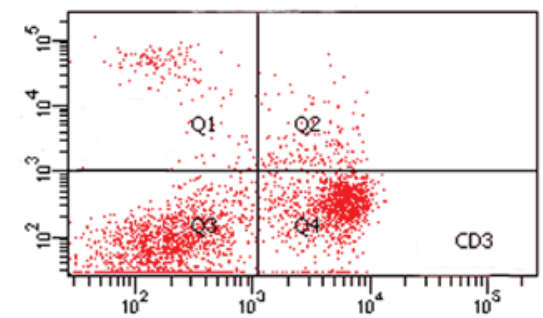

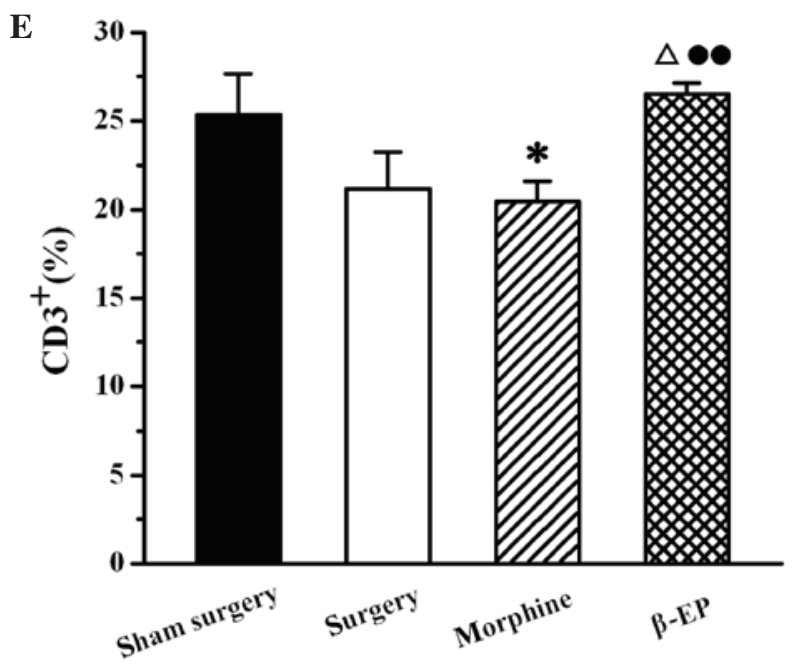

Figure 5. Effect of opioid treatment on $\mathrm{CD}^{+}$cells in a rat model of bone cancer pain. Morphine treatment induced a reduction of the content of $\mathrm{CD} 3^{+}$cells However, $\beta$-EP treatment caused a significant elevation of the CD3 ${ }^{+}$cell content. Flow cytometry shows $\mathrm{CD} 3^{+}$cells in the spleen of the (A) Sham surgery, (B) Surgery, (C) Morphine and (D) $\beta$-EP. (E) Quantification of (A-D). ${ }^{*} \mathrm{P}<0.05$ vs. the sham surgery group; ${ }^{\Delta} \mathrm{P}<0.05$ vs. the surgery group; ${ }^{*} \mathrm{P}<0.01$ vs. the morphine group. $n=8-10 . \beta$-EP, $\beta$-endorphin.

Effects of opioids on plasma IL-2 levels in a rat model of bone cancer pain. No significant difference was found among the sham surgery, surgery, morphine and $\beta$-EP groups with regard to plasma IL-2 level ( $\mathrm{P}>0.05$; Fig. 8).

\section{Discussion}

In the present study, the analgesic effect and immune modulating function of a homogenous opioid peptide (rat source $\beta$-EP) and heterogenous opioid (plant source morphine) were compared in a bone cancer pain model. It was found that both $\beta$-EP and morphine have good analgesic effects in this bone cancer pain model, and that the analgesia provided by of morphine was stronger than that of $\beta$-EP. Morphine treatment reduced the spleen $\mathrm{T}$ cell growth rate and the content of $\mathrm{T}$ cell subtypes $\left(\mathrm{CD}^{+}, \mathrm{CD}^{+}\right.$and $\mathrm{CD}^{+}$cells), whereas $\beta$-EP administration had the opposite effects on those indices as well as the NK cell cytotoxicity. Morphine and $\beta$-EP each had no effect on plasma IL-2 levels. These results demonstrate that the homogenous opioid had a positive effect on cancer pain.

Bone cancer pain in the most commonly used model of cancer pain, and many researchers have successfully established calcaneus, tibial and femur bone cancer pain models. Injection of Walker 256 cells into a tibial cavity can be used to study the mechanism of bone cancer pain. Mao-Ying et al reported that bone cancer developed from intra-tibial Walker 256 cells induced ambulatory pain and mechanical allodynia, and also reduced weight bearing, but that thermal hyperalgesia was not observed after Walker 256 cell inoculation (19). A previous study by the present team had similar results; it found that in a bone cancer model induced by the injection of Walker 256 cells into the tibial cavity, the rats had mechanical allodynia and spontaneous pain on days 4-22, and thermal hyperalgesia appeared in the intermediate stage (20). It was also found that the tibial cavity injection of Walker 256 cells in the bone cancer model induced a reduction in PWTs. 
A

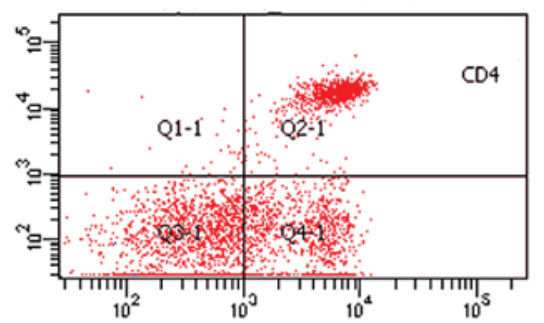

C

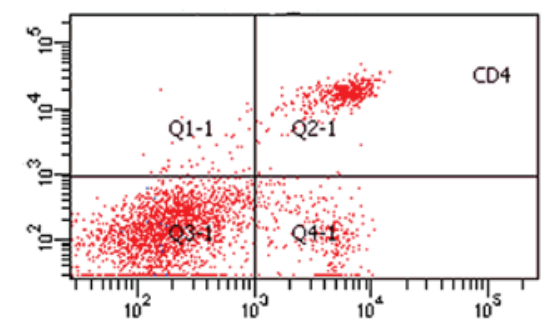

B

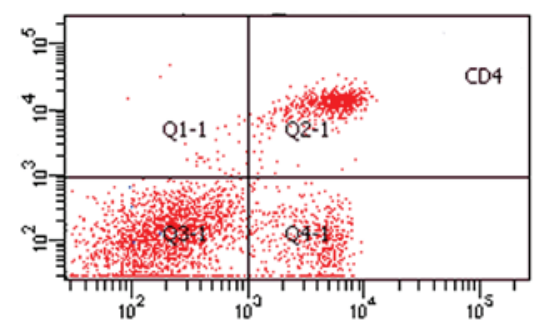

D

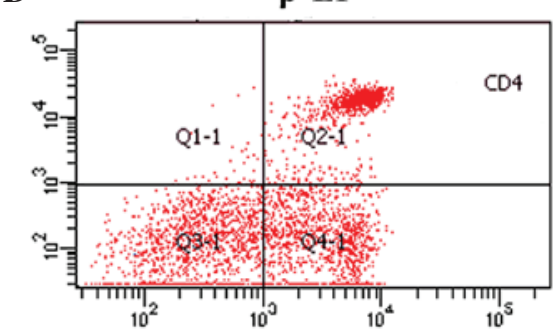

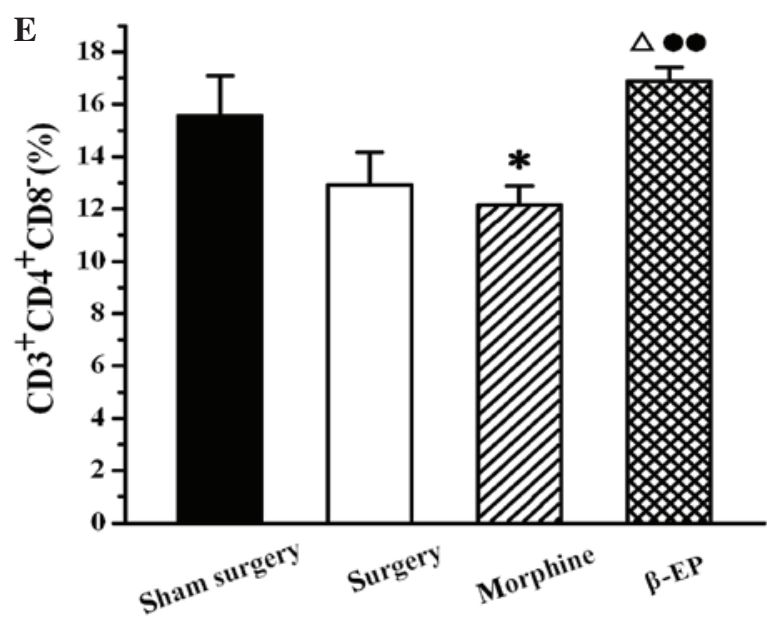

Figure 6. Effect of opioid treatment on $\mathrm{CD}^{+}{ }^{+}$cells in a rat model of bone cancer pain. $\beta$-EP treatment increased the content of $\mathrm{CD} 4^{+}$cells, but morphine treatment decreased them. Flow cytometry shows CD4 ${ }^{+}$cells in the spleen of the (A) Sham surgery, (B) Surgery, (C) Morphine and (D) $\beta$-EP. (E) Quantification of (A-D). ${ }^{*} \mathrm{P}<0.05$ vs. the sham surgery group; ${ }^{\Delta} \mathrm{P}<0.05$ vs. the surgery group; ${ }^{*} \mathrm{P}<0.01$ vs. the morphine group. $\mathrm{n}=8$ - 10 . $\beta$-EP, $\beta$-endorphin.

A number of studies have demonstrated that NK cells are able to kill tumor target cells in vitro and in vivo in animal models (21-23). Studies have shown that decreased NK cell activity is associated with the growth and development of a variety of cancers in humans (24) and animals (25), and NK cells protect against the metastatic spread of tumor cells (26). Multiple studies have provided evidence that morphine, a typical exogenous opiate, is involved in inhibiting the innate immune response (27). It has been reported that NK cell immune function is downregulated by morphine in vivo (28). NK cells are the first line of defense of the immune system, with a key role in the host defense against tumor cells (29). NK cells represent a unique subset of lymphocytes that have no restriction by major histocompatibility complex (MHC) antigens, are important in the initiation of tumor development and have the ability to lyse certain tumor cells without the requirement for prior immune sensitization of the host $(30,31)$. Not all kinds of opioids share the same immunosuppressive effects. It has been found that $\beta$-EP, an endogenous opioid peptide, promotes innate immune function and reduces the incidence of cancer in rat models (32). $\beta$-EP can also increase peripheral NK cell activities; in vitro differentiated $\beta$-EP cells when transplanted into the paraventricular nucleus improved NK cell cytolytic function in model rats (33). In the present study, intraperitoneal morphine and $\beta$-EP administration had different effects on NK cell cytotoxic activity. The systemic injection of rat source $\beta$-EP, a homogenous opioid peptide, increased the NK cell cytotoxicity of the rats with bone cancer pain, while the systemic injection of morphine, a heterogenous opiate, did not have such an effect.

In the present study, in addition to reducing the immune function of NK cells, morphine treatment also inhibited T cell function. It has been suggested that the immune system is able to detect and reject incipient tumors, and that total $\mathrm{T}$ cells $\left(\mathrm{CD}^{+}\right)$, helper $\mathrm{T}$ cells $\left(\mathrm{CD}^{+}\right)$and cytotoxic $\mathrm{T}$ cells $\left(\mathrm{CD}^{+}\right)$ play key roles in tumor immunology (34). $\mathrm{CD} 8^{+}$cells are traditionally considered to be the major mediators of an effective antitumor response by $\mathrm{T}$ cells. This is based on the pronounced cytotoxic activity of $\mathrm{CD} 8^{+} \mathrm{T}$ cells exhibited in vitro, and the observation that tumors capable of evading attack by $\mathrm{CD} 8^{+}$ T cells may have altered or downregulated expression of MHC class I antigens (35-37). Furthermore, in a study involving a 

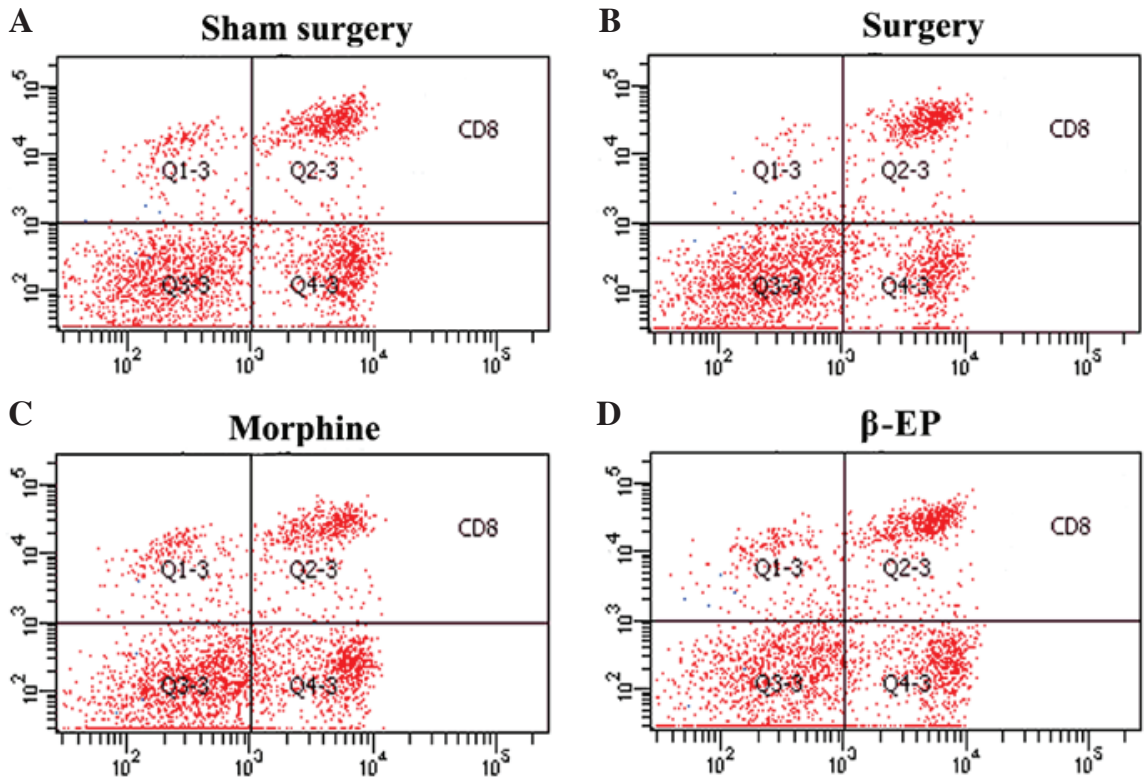

D
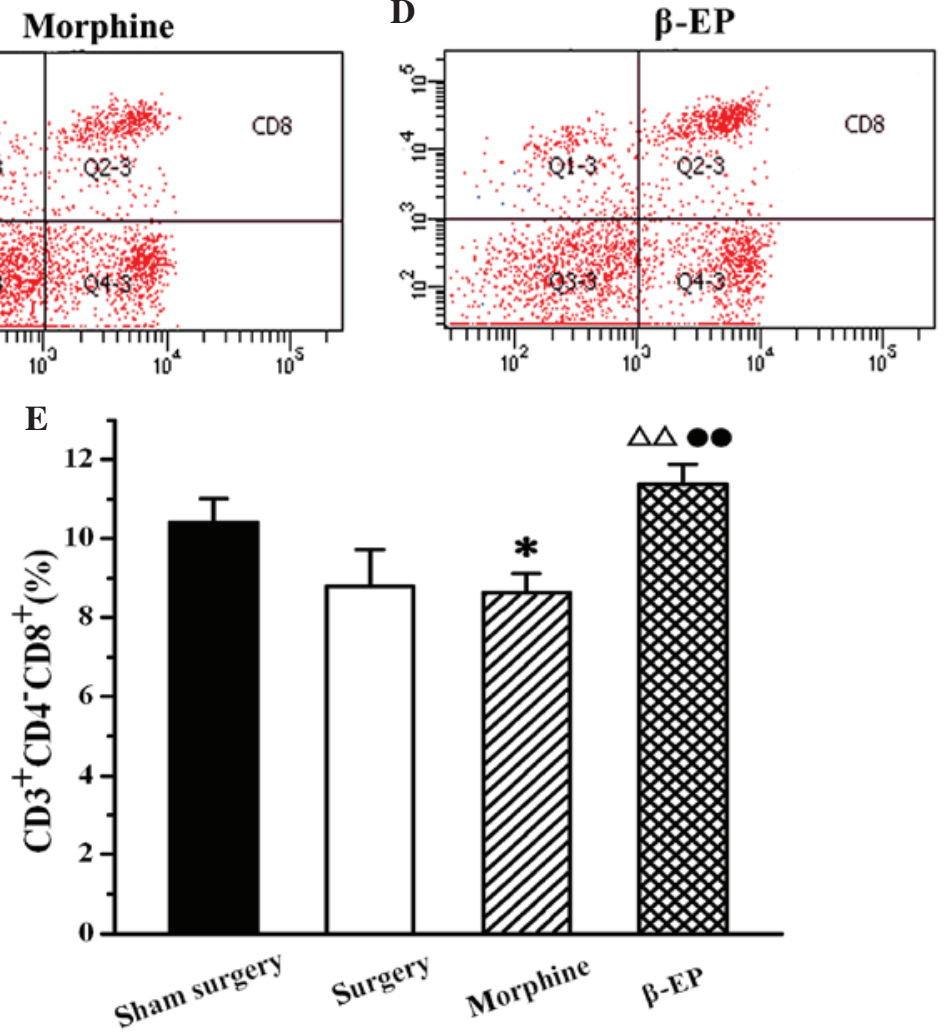

Figure 7. Effect of treatment with two different opioids on $\mathrm{CD} 8^{+}$cells in a rat model of bone cancer pain. $\beta$-EP treatment increased the content of CD8 ${ }^{+}$cells, but morphine treatment decreased them. Flow cytometry shows $\mathrm{CD}^{+}$cells in the spleen of the (A) Sham surgery, (B) Surgery, (C) Morphine and (D) $\beta$-EP. (E) Quantification of (A-D). " $\mathrm{P}<0.05$ vs. the sham surgery group; ${ }^{\Delta \Lambda} \mathrm{P}<0.01$ vs. the surgery group; ${ }^{*} \mathrm{P}<0.01$ vs. the morphine group. $\mathrm{n}=8-10$. $\beta$-EP, $\beta$-endorphin.

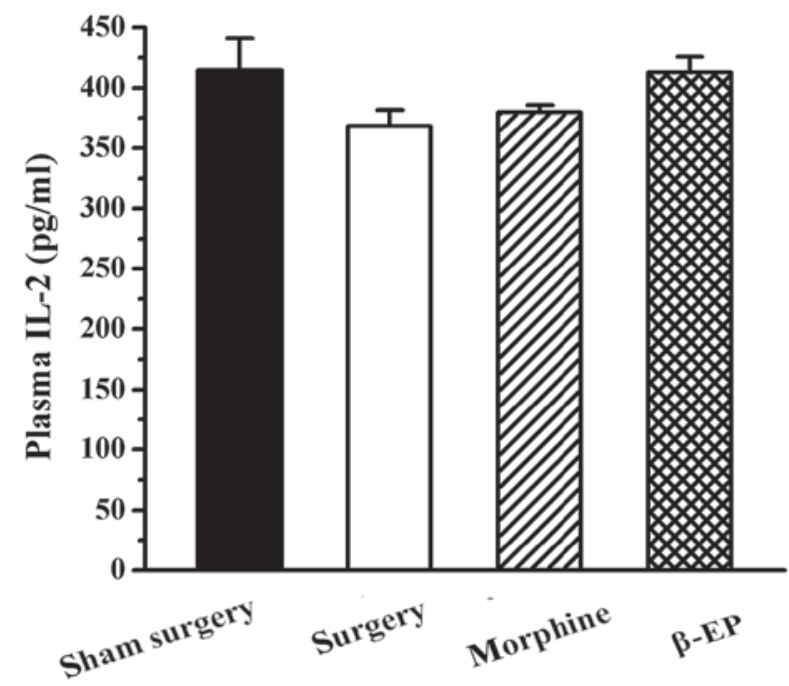

Figure 8. Effect of opioid treatment on plasma IL-2 levels in a rat model of bone cancer pain. No significant differences of plasma IL-2 level were observed among the sham surgery, surgery, morphine and $\beta$-EP groups. $\mathrm{n}=8-9$. $\beta$-EP, $\beta$-endorphin; IL, interleukin. transgenic mouse with MHC class I-restricted T cell receptors, it was found that $\mathrm{CD} 8^{+} \mathrm{T}$ cells maintained an antitumor effect when $\mathrm{CD}^{+}{ }^{+} \mathrm{T}$ cells were absent (38). Conflicting with these observations, other studies have indicated that the antitumor effects of $\mathrm{CD}^{+} \mathrm{T}$ cells alone are limited $(39,40)$. CD $4^{+}$cells that were limited by MHC II of themselves recognized exogenous antigen peptides (about 13-17 amino acids long). Thus, the MHC class II status of tumor cells is of importance in the immune response of $\mathrm{CD}^{+} \mathrm{T}$ cells to tumors. However, a number of studies have indicated that $\mathrm{CD}^{+} \mathrm{T}$ cells contribute to the eradication of tumors even in the absence of $\mathrm{CD} 8^{+} \mathrm{T}$ cells $(41,42)$. Cytotoxic $\mathrm{CD} 4^{+} \mathrm{T}$ cells have been shown to be capable of directly eliminating tumor cells that are MHC class II positive, in addition to indirectly killing tumor cells that lack MHC class II expression $(43,44)$. In the present study, it was found that the systemic injection of rat-derived $\beta$-EP, a homogenous opioid peptide, increased $\mathrm{CD}^{+}, \mathrm{CD}^{+}$and $\mathrm{CD} 8^{+}$ $\mathrm{T}$ cell subtype expression in a rat model of bone cancer pain, while the systemic injection of morphine, a heterogenous opioid compound, reduced their expression. 
In conclusion, morphine and $\beta$-EP exhibited good analgesic effects in the rat model of bone cancer pain, and the analgesia provided by morphine was stronger than that of $\beta$-EP. Morphine and $\beta$-EP administration in vivo have no significant effect on the secretion of IL-2 by T cells. With regard to T cell proliferation rate, the effects of the two different types of opioids differed; morphine suppressed $\mathrm{T}$ cell proliferation and $\beta$-EP increased it. The opioid compounds from different sources exhibited different effects on the adaptive cell immune; the homogenous opioid peptide $\beta$-EP increased the adaptive cell immune function.

\section{Acknowledgements}

This study was supported by the National Natural Science Fund of China (grant no. 81102643) and the State Administrative Bureau of Traditional Chinese Medicine (Acupuncture) of Key Subjects Construction Funding [grant no. (2009) 30].

\section{References}

1. Mercadante S and Fulfaro F: Management of painful bone metastases. Curr Opin Oncol 19: 308-314, 2007.

2. Marcus DA: Epidemiology of cancer pain. Curr Pain Headache Rep 15: 231-234, 2011

3. Pignon T, Fernandez L, Ayasso S, Durand MA, Badinand D and Cowen D: Impact of radiation oncology practice on pain: A cross-sectional survey. Int J Radiat Oncol Biol Phys 60: 1204-1210, 2004.

4. Rietman JS, Dijkstra PU, Debreczeni R, Geertzen JH, Robinson DP and De Vries J: Impairments, disabilities and health related quality of life after treatment for breast cancer: A follow-up study 2.7 years after surgery. Disabil Rehabil 26: 78-84, 2004.

5. Wilson KG, Graham ID, Viola RA, Chater S, de Faye BJ, Weaver LA and Lachance JA: Structured interview assessment of symptoms and concerns in palliative care. Can J Psychiatry 49: 350-358, 2004

6. van den Beuken-van Everdingen MH, de Rijke JM, Kessels AG, Schouten HC, van Kleef M and Patijn J: Prevalence of pain in patients with cancer: A systematic review of the past 40 years. Ann Oncol 18: 1437-1449, 2007.

7. Honore P, Rogers SD, Schwei MJ, Salak-Johnson JL, Luger NM, Sabino MC, Clohisy DR and Mantyh PW: Murine models of inflammatory, neuropathic and cancer pain each generates a unique set of neurochemical changes in the spinal cord and sensory neurons. Neuroscience 98: 585-598, 2000.

8. Schwab JM, Zhang Y, Kopp MA, Brommer B and Popovich PG: The paradox of chronic neuroinflammation, systemic immune suppression, autoimmunity after traumatic chronic spinal cord injury. Exp Neurol 258: 121-129, 2014.

9. Chen HY, Li SG, Cho WC and Zhang ZJ: The role of acupoint stimulation as an adjunct therapy for lung cancer: A systematic review and meta-analysis. BMC Complement Altern Med 13: $362,2013$.

10. Sacerdote P: Opioid-induced immunosuppression. Curr Opin Support Palliat Care 2: 14-18, 2008.

11. Smith RJ, Rhodes K, Paciotti B, Kelly S, Perrone J and Meisel ZF: Patient perspectives of acute pain management in the era of the opioid epidemic. Ann Emerg Med 66: 246.-252.e1, 2015.

12. Kostev K, Wartenberg F, Richter H, Reinwald $M$ and Heilmaier C: Persistence with opioid treatment in Germany in patients suffering from chronic non-malignant or cancer pain. Curr Med Res Opin 31: 1157-1163, 2015.

13. Deyo RA, Von Korff M and Duhrkoop D: Opioids for low back pain. BMJ 350: g6380, 2015.

14. Stefano GB, Fricchione G, Goumon Y and Esch T: Pain, immunity, opiate and opioid compounds and health. Med Sci Monit 11: MS47-MS53, 2005.

15. Vallejo R, de Leon-Casasola O and Benyamin R: Opioid therapy and immunosuppression: A review. Am J Ther 11: 354-365, 2004

16. Sacerdote P: Opioids and the immune system. Palliat Med 20 (Suppl 1): S9-S15, 2006.
17. Fang JQ, Du JY, Liang Y and Fang JF: Intervention of electroacupuncture on spinal p38 MAPK/ATF-2/VR-1 pathway in treating inflammatory pain induced by CFA in rats. Mol Pain 9: 13, 2013.

18. Poli A, Brons NH, Ammerlaan W, Michel T, Hentges F, Chekenya $M$ and Zimmer J: Novel method for isolating untouched rat natural killer cells with higher purity compared with positive selection and fluorescence-activated cell sorting. Immunology 131: 386-394, 2010.

19. Mao-Ying QL, Zhao J, Dong ZQ, Wang J, Yu J, Yan MF, Zhang YQ, Wu GC and Wang YQ: A rat model of bone cancer pain induced by intra-tibia inoculation of Walker 256 mammary gland carcinoma cells. Biochem Biophys Res Commun 345: 1292-1298, 2006.

20. Jun-Ying D, Yi L, Yi-Tian C, et al: Functional evaluation of spleen $T$ lymphocytes in the rat model of Walker-256 bone cancer pain. Zhong Guo Bi Jiao Yi Xue Za Zhi 24: 8-13MS, 2014 (In Chinese).

21. Wennerberg E, Kremer V, Childs R and Lundqvist A: CXCL10-induced migration of adoptively transferred human natural killer cells toward solid tumors causes regression of tumor growth in vivo. Cancer Immunol Immunother 64: 225-235, 2015.

22. Ardolino M, Azimi CS, Iannello A, Trevino TN, Horan L, Zhang L, Deng W, Ring AM, Fischer S, Garcia KC and Raulet DH: Cytokine therapy reverses NK cell anergy in MHC-deficient tumors. J Clin Invest 124: 4781-4794, 2014.

23. Zitvogel L and Kroemer G: Cytokines reinstate NK cell-mediated cancer immunosurveillance. J Clin Invest 124: 4687-4689, 2014.

24. Shereck E, Satwani P, Morris E and Cairo MS: Human natural killer cells in health and disease. Pediatr Blood Cancer 49: 615-623, 2007.

25. Saijo N, Ozaki A, Beppu Y, Takahashi K, Fujita J, Sasaki Y, Nomori H, Kimata M, Shimizu E and Hoshi A: Analysis of metastatic spread and growth of tumor cells in mice with depressed natural killer activity by anti-asialo GM1 antibody or anticancer agents. J Cancer Res Clin Oncol 107: 157-163, 1984.

26. Sacerdote P: Opioid-induced immunosuppression. Curr Opin Support Palliat Care 2: 14-18, 2008.

27. Chang MC, Fan SZ, Hsiao PN, Cheng WF and Sun WZ: Influence of morphine on host immunity. Acta Anaesthesiol Taiwan 49: 105-108, 2011.

28. Brown JN, Ortiz GM, Angel TE, Jacobs JM, Gritsenko M, Chan EY, Purdy DE, Murnane RD, Larsen K, Palermo RE, et al: Morphine produces immunosuppressive effects in nonhuman primates at the proteomic and cellular levels. Mol Cell Proteomics 11:605-618, 2012.

29. Kheav VD, Busson M, Scieux C, Peffault de Latour R, Maki G, Haas P, Mazeron MC, Carmagnat M, Masson E, Xhaard A, et al: Favorable impact of natural killer cell reconstitution on chronic graft-versus-host disease and cytomegalovirus reactivation after allogeneic hematopoietic stem cell transplantation. Haematologica 99: 1860-1867, 2014.

30. Jacobs B and Ullrich E: The interaction of NK cells and dendritic cells in the tumor environment: how to enforce NK cell \& DC action under immunosuppressive conditions? Curr Med Chem 19: 1771-1779, 2012.

31. JX Zhao: Advances of enhancing cytotoxicitiy of NK cells. Chinese Journal of Cancer Prevention \& Treatment 16:1267-1271. 2009.

32. Schweizerhof M, Stösser S, Kurejova M,Njoo C, Gangadharan V, Agarwal N, Schmelz M, Bali KK, Michalski CW, Brugger S, et al: Hematopoietic colony-stimulating factors mediate tumor-nerve interactions and bone cancer pain. Nat Med 15: 802-807, 2009.

33. Sarkar DK, Murugan S, Zhang C and Boyadjieva N: Regulation of cancer progression by $\beta$-endorphin neuron. Cancer Res 72: 836-840, 2012 .

34. Koebel CM, Vermi W, Swann JB, Zerafa N, Rodig SJ, Old LJ, Smyth MJ and Schreiber RD: Adaptive immunity maintains occult cancer in an equilibrium state. Nature 450: 903-907, 2007.

35. Antony PA, Piccirillo CA, Akpinarli A, Finkelstein SE, Speiss PJ, Surman DR, Palmer DC, Chan CC, Klebanoff CA, Overwijk WW, et al: CD8+ T cell immunity against a tumor/self-antigen is augmented by CD4+ T helper cells and hindered by naturally occurring $\mathrm{T}$ regulatory cells. $\mathrm{J}$ Immunol 174: 2591-2601, 2005.

36. Fujii H, Arakawa A, Utsumi D, Sumiyoshi S, Yamamoto Y, Kitoh A, Ono M, Matsumura Y, Kato M, Konishi K, et al: CD8 ${ }^{+}$ tumor-infiltrating lymphocytes at primary sites as a possible prognostic factor of cutaneous angiosarcoma. Int J Cancer 134: 2393-2402, 2014. 
37. Chen Y, Ayaru L, Mathew S, Morris E, Pereira SP and Behboudi S: Expansion of anti-mesothelin specific CD4+ and CD8+ T cell responses in patients with pancreatic carcinoma. PLoS One 9: e88133, 2014

38. Hanson HL, Donermeyer DL, Ikeda H, White JM, Shankaran V, Old LJ, Shiku H, Schreiber RD and Allen PM: Eradication of established tumors by CD8+ T cell adoptive immunotherapy. Immunity 13: 265-276, 2000.

39. Arancibia-Carcamo CV, Osawa H, Arnett HA, Háskova Z George AJ, Ono SJ, Ting JP and Streilein JW: A CIITA-independent pathway that promotes expression of endogenous rather than exogenous peptides in immune-privileged sites. Eur J Immunol 34: 471-480, 2004

40. Boon T, Coulie PG, Van den Eynde BJ and van der Bruggen P: Human $\mathrm{T}$ cell responses against melanoma. Annu Rev Immunol 24: 175-208, 2006.
41. Segal BM, Glass DD and Shevach EM: Cutting Edge: IL-10-producing CD4+ T cells mediate tumor rejection. J Immunol 168: 1-4, 2002

42. Quezada SA, Simpson TR, Peggs KS, Merghoub T, Vider J, Fan X, Blasberg R, Yagita H, Muranski P, Antony PA, et al: Tumor-reactive CD4(+) T cells develop cytotoxic activity and eradicate large established melanoma after transfer into lymphopenic hosts. J Exp Med 207: 637-650, 2010

43. Noyan F, Lieke T, Taubert R, Sievers M, Dywicki J, Hapke M, Falk CS, Manns MP, Jaeckel E and Hardtke-Wolenski M: Naive tumour-specific CD4+ T cells were efficiently primed in acute lymphoblastic leukaemia. Scand J Immunol 80: 161-168, 2014.

44. Snook AE, Magee MS, Schulz S and Waldman SA: Selective antigen-specific CD4(+) T-cell, but not CD8(+) T- or B-cell, tolerance corrupts cancer immunotherapy. Eur J Immunol 44: 1956-1966, 2014. 